Dossiê: Religião e globalização

\title{
Encarte digital
}

\section{A narrativa utópica contemporânea \\ O califado, o martírio e a violência política}

The contemporary utopian narrative

The caliphate, martyrdom and political violence

Jacques A. Wainberg*

\begin{abstract}
Resumo: A função social das grandes narrativas pode ser documentada hoje em dia no discurso político de tom revolucionário que os grupos salafistas divulgam através de vários meios de comunicação. O califado, o martírio e a violência política são três elementos chaves deste novo tipo de retórica. Entre seus efeitos está a ação militar e religiosa promovida em nome do pan-islamismo. O caso também documenta o papel que tais narrativas utópicas têm na formação das identidades humanas.
\end{abstract}

Palavras-chaves: Utopia. Narrativa. Salafismo.

Abstract: The role performed by grand narratives can be documented nowadays in political and revolutionaries discourses that Salafist groups are disseminating through various means of communication. The caliphate, martyrdom and political violence are three key subjects of this new type of rhetoric. The military and religious actions on behalf on pan-islamism are among its main effects. This case also documents the role these kind of utopian narratives have in the consolidation of human identities.

Keywords: Utopia. Narrative. Salafism.

Ao contrário do que supõe a crítica pós-moderna (Lyotard, 2008) as grandes narrativas não pereceram. Elas persistem porque sua função é essencial à vida humana. Através delas os grupos humanos consolidam identidades culturais. Outra propriedade é sua capacidade de organizar as ocorrências numa fábula e prover às pessoas esperança. Sua transmissão ocorre de formas variadas, principalmente a via religiosa. É fácil verificar que em toda

* Doutor em Ciências da Comunicação pela Universidade de São Paulo, professor no PPG em Comunicação Social na Pucrs em Porto Alegre, RS, Brasil<jacqalwa@pucrs.br>.

\begin{tabular}{|c|c|c|c|c|c|}
\hline Civitas & Porto Alegre & v. 14 & n. 3 & p. e53-e66 & set.-dez. 2014 \\
\hline
\end{tabular}


comunidade o tempo é marcado pelo drama relatado, seus personagens e a moral de sua história.

Da mesma forma que ocorre nas narrativas populares disseminadas através da mídia, também esta, a cultivada na tradição oral e nos rituais sagrados, tem personagens, um cenário e um plot. Seu efeito é sistêmico, pois organiza a maneira como determinado público percebe a realidade, sua herança e sua missão. A interpretação do significado do que é dito e repetido varia desde um polo literalista e rígido a outro, aberto e disponível à polissemia. $\mathrm{O}$ confronto entre as duas correntes por isso mesmo é inevitável. A primeira quer disseminar uma mensagem e está preocupada por decorrência com o sentido do conteúdo. A segunda, ao contrário, está mais fascinada com o enredo.

As grandes narrativas servem aos propósitos da educação coletiva. Ou seja, elas decorrem necessariamente de um contexto cultural determinado. Em boa medida, a elaboração de uma narrativa deste porte amadurece ao longo do tempo. Adquire com o tempo a solidez de uma rocha. Ela articula e organiza os eventos que se sucedem na linha do tempo, apresenta os personagens que se enlaçam na trama, elabora sobre os dilemas do drama, e por fim lega às gerações um ensinamento na forma de um dogma. Depois surgem as histórias da história que se espalham como combustível das mentes. Seu efeito é contagioso. E é graças aos contadores destas histórias que se consolidam as tradições que marcam por fim seus territórios.

Segundo os ensinamentos da narratologia (Felluga, 2013), o ato narrativo é o processo de construir ou fazer tais histórias. Nele interferem hoje em dia atores variados, entre eles os pregadores religiosos, a mídia e os educadores. $\mathrm{O}$ grau de liberdade que eles possuem para agregar e alterar tal herança varia de sociedade a sociedade, de cultura a cultura. Boa parte das disputas retóricas decorre do mal-estar que os guardiões da tradição têm com as vocações mais rebeldes dispostas até mesmo a dissentir.

O poder mágico das histórias é sua capacidade de enlaçar as gerações. Para isso, o drama deve ser envolvente. Os personagens em confronto devem ser paradigmáticos. $\mathrm{O}$ conflito e sua solução devem ser atemporais. Em última instância, a função desses textos canônicos é ajudar o leitor/ouvinte a fazer sentido do seu mundo. Autorizar a ambiguidade, como as vozes liberais sempre propõem, é, na visão literalista, jogar o povo na incerteza. E o que eles temem é que neste campo movediço de crise moral possa surgir a heresia e a apostasia.

Todos ouvem e contam histórias em todos os lugares em todos os tempos. A obra de Joseph Campbell (2007) descreve os padrões destas narrativas que aparecem nos mitos, nos rituais religiosos e nos dramas em geral. Seu ensinamento foi apropriado na cinematografia que acolheu sua principal 
conclusão sobre o monomito, ou seja, o fato de que sempre se conta a mesma história em infinitas versões.

Ocorre que as versões são também relevantes, provavelmente mais relevantes que esta base humana comum que ambiciona se expressar através das utopias políticas, literárias e religiosas. E as versões remetem à singularidade dos grupos humanos, suas idiossincracias e identidades.

\section{O califado}

Hoje em dia, em boa parte do Oriente e da Ásia, e mesmo do Ocidente, não são as ideias socialistas, feministas ou ecológicas que alimentam tais narrativas de encantamento. É o islamismo que ocupa este espaço onde se acalenta os sonhos de uma nova sociedade.

A distância hoje observada entre alguns hábitos políticos marcantes do Ocidente e os existentes em várias regiões do Oriente parecia no passado estar diminuindo com a intensificação dos contatos culturais e políticos entre os dois universos após a invasão do Egito por Napoleão em 1798. Esse período usualmente é descrito como sendo a Renascença árabe, ou Al-Nahda. Nele, o desenvolvimento de uma nova literatura no Egito e noutros países da região, o aparecimento de traduções ao árabe de obras ocidentais e várias iniciativas de modernização e reforma estimulada por Muhammad Ali, o vice-rei do Egito no período do Império Otomano, davam esta impressão de que a aproximação entre os dois mundos era possível.

A ação de personagens como Rifa'a Rafi' el-Tahtawi (1801-1873), que retornou de sua estadia em Paris -onde serviu como Imã dos cadetes egípcios que treinavam na academia militar francesa- fortemente influenciado pela cultura ocidental, apoiando o parlamentarismo, a educação das mulheres e algum grau de secularismo, tem sido destacada por autores que apontam aquele período como uma oportunidade perdida neste diálogo inter-civilizacional.

Em parte do mundo árabe e islâmico predomina agora o antigo sonho do restabelecimento do califado. Ele tornou-se também um dos principais objetivos da atuação política e militar dos grupos salafistas. Este desejo é documentado, por exemplo, numa carta que o líder da Al-Qaeda, Ayman alZawahiri, enviou ao comandante da organização no Iraque, Abu Musab alZarqawi. Nela ele diz que a ambição dos militantes é o estabelecimento de um regime islâmico que começa no Iraque, chega aos países seculares próximos, assalta Israel e vai dali adiante. Ele sugere na correspondência que logo após a expulsão dos americanos um emirado deveria ser formado no Iraque. O que estava em jogo, segundo suas palavras, era o estabelecimento a seguir de um califado "na maneira do Profeta". 
Portanto, cabe entender o papel que o califado desempenha nesta narrativa e neste imaginário social e religioso. Parece haver certa nostalgia popular por este período de aparência gloriosa no qual os sunitas se organizaram em torno da liderança de Abu Bakr que sucedeu o Profeta após sua morte. Abu Bakr foi sucedido por Umar, esse por Uthman e esse por Ali. Esses quatro, conhecidos por Rashidum, são considerados como califas divinamente inspirados. Eles ocupam o papel místico de fundadores da civilização sunita.

O ramo xiita acolheu Ali, o primo e genro do Profeta, como califa. Muawiya sucedeu Ali e fundou pelas armas a dinastia Umaiáda (661-750) instalando-a em Damasco. Essa dinastia xiita foi derrubada em 750 pela família Abássida que instalou seu reino em Bagdá (749). Em 1258, os abássidas fugiriam para o Egito após a destruição do seu reino pelos mongóis. Mas este país acabaria conquistado pelos otomanos em 1517. Até esse momento o título de califa era adotado pelos sultões turcos somente de forma esporádica. Depois se tornou frequente. A partir do sultão Selim I, o título de Califa passou a ser utilizado por todos os seus sucessores até o último deles, Mohammad VI, em 1924, quando foi deposto pela revolução republicana liderada pelo fundador da Turquia moderna, Kemal Atatürk. Na Espanha, um sobrevivente umaiáda acabaria fundando outro califado ainda, o de Córdova (existiu de 780 a 1301). Mais um foi estabelecido pelos fatímidas no norte da África e no Egito (969-1171). Um último, denominado de Califado de Sokoto, foi fundado em 1800 na região da Nigéria. Tornou-se um dos mais poderosos impérios daquela região subsistindo até 1903 . Finalmente o disputado título ficou nas mãos do rei da Arábia, Hussein ibn Ali, que abdicou e cedeu o título de Califa ao fundador da moderna Arábia Saudita, Ibn Saud.

Desde 1924, vários encontros islâmicos têm tentado restabelecer um novo e revigorado califado. Esta tem sido igualmente a meta de vários movimentos pan-islâmicos. Líderes muçulmanos da Índia, por exemplo, lideraram na década de 20 sem sucesso o movimento pela manutenção do califado na Turquia. Mas o vazio político e simbólico não foi preenchido. De tempo em tempo algum dignitário islâmico reivindica o título. Busca assim recriar a glória e a mística do antigo regime que unia o poder secular e religioso numa única autoridade.

O califado exerce hoje fascínio sobre os grupos salafistas por representar um período histórico no qual a narrativa islâmica foi capaz de constituir uma civilização que se projetava por vários continentes e cultuava uma mesma tradição. Sua vocação evangelizadora e universal deriva do apostolado (principalmente sunita) estabelecido após a morte do Profeta. No entanto, suas divisões políticas e nacionalistas são interpretadas como sintomas de um 
fracasso que devem ser superados agora através da militância religiosa (dawa) e militar (jihad).

Vários grupos e partidos políticos advogam hoje em dia a ideia da restauração do califado, seja através da ação política como propõe o Hizb utTahrir (Partido da Liberação), uma organização pan-islâmica sunita que atua em mais de 40 países, seja pela força (este é o caso da Al-Qaeda). O mesmo objetivo é perseguido pela Irmandade Muçulmana e pela Jemaah Islamiyah, que age na Indonésia, Malásia, Brunei, partes da Tailândia, nas Filipinas e Cambodja.

Os xiitas preferem designar o califado de imamato, ou seja, o reino liderado pelo imã. Após os 12 primeiros sucessores diretos de Ali, a nomeação deste imã xiita tornou-se igualmente polêmica, e a opção utilizada no Irã, a de que cabe aos juristas islâmicos nomear este líder, não é consensual. Existem divergências também em outras inúmeras áreas, como por exemplo, as condições que autorizam o impeachment de um califa.

O salafismo tem sido definido como uma 'ideologia religiosa'. Ela acusa a globalização cultural de ter influenciada nas modificações das crenças, hábitos e costumes venerados como sagrados e fundamentais à identidade islâmica e dos povos árabes. A pregação salafista não visa amparar o indivíduo, mas o público em geral. Assim sendo, esta corrente religiosa e política demanda lealdade de todos à comunidade. Seu fervor missionário visa mostrar ao muçulmano o que é necessário fazer e onde todos devem chegar.

Nesta doutrina, a violência é descrita como um meio justificável para se alcançar um fim sagrado. Esta pregação tem produzido resultados notáveis e inesperados. Exemplo é sua expansão no Paquistão onde grupos salafistas têm atacado de forma virulenta as demais correntes teológicas que competem consigo pelo domínio do imaginário dos crentes. Os salafistas de hoje, da mesma forma que os rebelados do Baader Meinhof, dos Montoneros, dos Tupamaros e de outros grupos revolucionários similares dos anos 60 e 70, advogam que o alvo de suas ações [revolucionárias] é o mundo todo.

\section{A violência}

Essa narrativa de tom revolucionário admite a violência. No passado ela encontrou amparo na argumentação de outros utopistas que desejavam com suas ações apagar rapidamente as marcas do velho mundo. Os rebelados esperam que destas ruínas possa emergir finalmente 'a nova sociedade'. Por isso a violência tem sido considerada por esses grupos radicais (entre os quais se destacavam no passado os anarquistas) uma forma de terapêutica social. 
Leon Trostky (1979), em sua defesa do terrorismo, diz que "o terror vermelho" era uma arma contra a burguesia que, como classe, recusava desaparecer. Ele pondera que não era e não deveria ser uma ação de violência individual cega - sempre condenável, mas uma atitude política justificável.

Como se sabe da história, esse "terror vermelho" logo se espalhou pelo território soviético através de prisões sem julgamento, da tortura e de assassinatos de suspeitos e de opositores ao novo regime comunista, em especial no período de 1918 a 1922. Execuções em massa foram realizadas em 1919. Milhares de pessoas foram enviadas à Sibéria. Neste território surgiu o Gulag, campo de morte e de trabalho forçado cuja criação antecedeu aos campos de concentração nazistas. Eles funcionaram naquele país de 1918 a 1956. Segundo dados soviéticos, pelo menos 1.053 .829 morreram nestes locais entre 1934 e 1953.

O mesmo fascínio pela violência foi cultivado ainda por inúmeros personagens políticos e intelectuais que exemplificaram com suas obras e atitudes pessoais a crença no seu efeito redentor e curativo. Frantz Fanon é um deles. Nascido na Martinica, ele serviu no exército francês na Segunda Guerra Mundial. Graduou-se em medicina, tornando-se em 1953 chefe do Departamento de Psiquiatria de um hospital argelino, país que nos anos 50 ainda era colônia francesa. Por ser negro, sofreu o racismo e sua primeira obra Pele negra, máscaras brancas, de 1952 (Fanon, 1968), tratou desta temática. A partir de 1954, ele passou a colaborar secretamente com os rebeldes nacionalistas argelinos. Dois anos depois, renunciaria ao cargo no hospital passando a atuar abertamente contra os franceses ao lado do FLN (Frente de Libertação Nacional). Logo se tornou num dos principais ideólogos deste movimento desenvolvendo a partir de então uma ampla teoria em favor da luta anticolonial. Sua próxima obra Os condenados da terra (1961[1979]) elaboraria uma visão política cuja influência foi extraordinária nos movimentos rebeldes das décadas de 60 e 70. Visto como uma espécie de profeta da luta revolucionária, Fanon diz na obra que somente através da violência pode ser realizada a revolução e que dela nasce um novo homem e uma nova cultura. Só assim é possível o ser humano libertar-se das "algemas" físicas e psicológicas do colonialismo racista. Segundo essa visão, a violência tem um efeito catártico que "regenera" e unifica a população subjugada. Sua prosa militante conclamava o leitor a deixar para trás crenças e sonhos cultivados e antigos amigos. Chegara a hora de mudar a maneira de se comportar. Um novo dia estava ao alcance. Para fazê-lo surgir deviam todos ser firmes, prudentes e resolutos. A relação de estima e simpatia com a Europa deveria ser abandonada de vez. Havia coisas melhores a fazer do que seguir os passos das tradições 
do Velho Mundo. Este jogo de produzir fascínio cego das novas gerações aos valores europeus tinha terminado. Este continente seguia rumo ao abismo, alertava Fanon. Cabia ao Terceiro Mundo começar uma nova história do Homem.

Apesar de sua curta vida - morreu aos 36 anos, da mesma forma que vários outros teóricos e militantes das revoluções comunistas: Lênin faleceu aos 54 anos; Amilcar Cabral, aos 49; Rosa Luxemburgo aos 48 e Che Guevara aos 39-, sua palavra influenciou vários líderes, entre eles Steve Biko na África do Sul (faleceu aos 31 anos) (Gibson, 2011). Exerceu igualmente influência sobre Ali Shariati, um dos principais ideólogos da revolução xiita que depôs o governo de Mohamad Reza Pahlavi, o Xá do Irã, em 1979.

A introdução escrita em 1961 por Jean Paul Sartre ao livro de Fanon ganhou enorme popularidade. Alarmou o establishment político francês, que se viu frontalmente atacado pela prosa anticolonial de seu mais iminente filósofo. Nela, ao defender sua militância, Jean Paul Sartre também advogou o direito à violência. De acordo com Sartre, as palavras de Fanon representavam os interesses de todo o Terceiro Mundo que se identificava e se expressava através de sua voz. Esta rebelião era uma obra em andamento, "que começa com a união de todos os colonizados sob o comando da classe campesina". Era isso que Fanon explicava aos seus irmãos da África, da Ásia e da América Latina, comenta Sartre. Dizia que todos juntos deveriam conquistar o socialismo revolucionário em todos os lugares, caso contrário cada um dos rebelados seria derrotado pelos antigos senhores. Todos deveriam ler Fanon, recomendava Sartre. Deveriam compreender que a violência do rebelado não era nem o ressurgimento de instintos selvagens nem a manifestação do ressentimento. Era o homem se recriando.

\section{O martírio}

Outro elemento frequente dessas narrativas revolucionárias é o martírio. Ele tem sido um elemento chave de discurso doutrinário que tem acompanhado não só os movimentos rebelados como também a de seus inimigos, os combatentes mobilizados pelos exércitos. A marinha americana, por exemplo, explodiu em quatro de agosto de 1804 o seu navio Intreprid juntamente com sua tripulação na baia de Trípoli onde estavam estacionadas as embarcações piratas inimigas. Naquela oportunidade, o Papa Pio VII daria sua benção e concederia um álibi moral aos suicidas dizendo: "O comandante americano, com uma pequena força e num curto período de tempo, fez mais pelo cristianismo do que a maior parte das poderosas nações da Cristandade fez por séculos!" 
Cabe lembrar que o suicídio foi utilizado como estratégia de luta no período da Segunda Guerra Mundial por pilotos japoneses que guiavam manualmente os torpedos e se explodiam junto ao alvo; pela Luftwaffe que atacou com missões suicidas as pontes soviéticas localizadas sobre o Rio Oder. Também voluntários suicidas integrantes do Viet Minh atacaram no Vietnã as tropas francesas com cinturões de explosivos colados ao corpo. Exemplo mais recente foi o ataque suicida dos militantes da $\mathrm{Al}$ Qaeda às torres gêmeas de Nova York, em setembro de 2011, ocasionando cerca de 3000 mortos.

Os Tigres Tâmeis que lutam desde 1976 pela criação de um estado tâmil independente no nordeste de Sri Lanka é o grupo que mais realizou incursões deste tipo. O grupo tornou-se mundialmente conhecido por cometer atrocidades contra civis, por assassinar autoridades e por recrutar criançassoldado. Foi o pioneiro na utilização de homens e mulheres-bomba.

Este tipo de ação tem sido imitado agora por várias organizações islâmicas que justificam suas ações com a figura retórica do martírio religioso. Foi o caso também do Irã. Na década de 1980, sob o manto dos cânticos religiosos, este país enviaria ondas de jovens voluntários desarmados, entre eles crianças de até nove anos de idade, para marchar sobre campos minados por seus inimigos iraquianos na guerra entre os dois países.

Embora a ideia do "martírio" seja evocada em situações distintas, ela expressa o fato de que o militante se conforma ao sacrifício. Muitas vezes este tipo de comportamento tem servido às gerações futuras de motivo para celebração e recordação. O martirizado é glorificado como herói, já que sua ação é voluntária, consciente e altruísta. Por ser um ato geralmente público, o martírio tem uma propriedade política. Ele também é celebrado porque em certas ocorrências o martirizado resiste de forma exemplar à violência que sofre. A oposição ativa dos fiéis à conversão religiosa forçada é exemplo deste tipo comportamento. Este foi o caso dos Quarenta Mártires do Brasil recordados pela Igreja Católica. Hoje, a festa litúrgica de 17 de julho recorda esses personagens que acabaram beatificados em 1854 pelo Papa Pio IX. Outros 150 fiéis assassinados em $1645 \mathrm{em}$ dois ataques realizados por soldados holandeses foram beatificados pelo Papa João Paulo II em 2000, durante as comemorações dos 500 anos do Brasil. Justino de Náblus, executado por ordens do Imperador Marco Aurélio é outro mártir da Igreja Católica.

Já os protestantes recordam Jan Hus, queimado vivo em 1415 em Praga após ser excomungado da Igreja Católica em 1410 e condenado pelo Concílio de Constança. Miguel Servet, teólogo, médico e filósofo aragonês, autor de uma cristologia não-trinitariana, também é recordado pelos protestantes por 
ter sido executado em 1553 na cidade de Bruxelas após o veredito de um julgamento papal.

Jesus e muitos de seus seguidores entre os primeiros cristãos que enfrentaram a perseguição e a morte decretada nas dez perseguições dos imperadores romanos (Nero, Domiciano, Trajano, Marco Aurélio, Sétimo Severo, Maximiano, Décio, Valeriano, Aureliano e Diocleciano) também são descritos como mártires. A ideia de "martírio" está igualmente presente na fé Bahai. Para esta religião de 23 milhões de pessoas que se desenvolveu na região do Punjab (entre o Paquistão e a Índia) a partir do século 14, o mártir é quem se sacrifica pela humanidade em nome de Deus. Já o sikhismo enquadra seus principais gurus nesta categoria uma vez que perderam a vida ora lutando contra o império mogol e ora contra outros inimigos. Por vezes ainda o martírio é referido como o combate contra um inimigo mais poderoso (é o caso, por exemplo, do militante islâmico que morre na jihad, a guerra classificada como sagrada). O suicídio de um mártir acaba tendo um significado político. Exemplo clássico são os eventos ocorridos em Massada.

Muito embora o suicídio seja altamente reprovado no Judaísmo, a recusa judaica ao domínio político e cultural romano em 73 da Era Comum culminou com o suicídio coletivo de todos os combatentes e de suas famílias concentrados naquela fortaleza próxima ao mar Morto. Também a rebelião macabeia contra o domínio político e cultural helênico culminou com atos suicidas que expressavam em última instância a rebelião política, religiosa e cultural do grupo oprimido. Ou seja, o judaísmo antigo esteve também impregnado pela cultura do martírio. A denominação de tal ato como Kidush Hashem (a Santificação do Nome) realça a relevância religiosa e política que se deu à resistência à assimilação religiosa e cultural. Embora o termo não apareça na Bíblia judaica, predomina a ideia de que todo e qualquer ato que honre a Deus deve ser rotulado como uma ação de santificação de Seu nome. O contrário é rotulado como desonra de Seu nome. O suicídio foi também praticado com este mesmo espírito em inúmeras comunidades de judeus europeus que foram atacados pelos cruzados.

Exemplos de personalidades celebradas como mártires não faltam. Sócrates é descrito como tal em Phaedo por Platão, por ter morrido defendendo suas ideias. O martírio de Hussein ibn Ali Abi Talib, neto do profeta Maomé, assassinado em 680 da Era Comum, em Karbala, Iraque, após perder uma rebelião contra o Califa Yazid, tornou-se numa narrativa central das tradições xiitas. O termo é aplicado igualmente no caso de Rav Akiva, um rabino tanaíta celebrado na tradição judaica. Acabou morto após ser torturado pelos romanos, acusado de não respeitar a proibição do ensino da Torá aos seus seguidores 
no conturbado período da revolta liderada por Simão Bar Kohba contra o império.

No caso do Islã, os casos recentes de suicídios políticos levados a cabo por militantes de grupos salafistas provocaram intenso debate teológico sobre sua validade. De um lado estão os que o autorizam. O suicida seria o shahid, o mártir. O termo é favorável ao que morre por uma causa a fim de testemunhar sua fé por Alá. Outros juristas e intérpretes do Islã, no entanto, condenam tal entendimento. Atacar não combatentes visando aterrorizar a comunidade é descrita por eles como um ato de "corrupção do mundo". Por isso, os críticos preferem rotular este tipo de investida não como "martírio suicida", mas como "martírio homicida", ou ainda como "martírio genocida".

Os mártires ajudam a fortalecer a coesão social e a identidade dos integrantes de grupos variados que se inspiram em seus atos e sofrimento. É o caso também de Al-Husayn ibn Mansur AL-Hallaj para os sufistas do Islã. Sua serenidade frente ao sofrimento e à tortura a que foi condenado por heresia pelo Califa Al-Muqtadir serve hoje como objeto de imitação e deslumbre a seus simpatizantes. Tiradentes no Brasil é também denominado de mártir por ter morrido por enforcamento em nome da Inconfidência.

\section{As disjunções}

Cabe assinalar que este tipo de culto à morte tem sido recurso retórico bastante utilizado nos discursos políticos, em especial nos momentos históricos graves em que os vocacionados à rebeldia apostam tudo, até mesmo a vida, na causa em jogo. Por vezes, essas ações e clamores niilistas acabam sendo celebrados em canto e verso. A Marselhesa, por exemplo, é um grito de guerra:

Avante, filhos da pátria!

As armas cidadãos!

Formai vossos batalhões!

Marchemos, Marchemos!

O hino de Portugal conclama a população para que ela marche contra os canhões:

Às armas, às armas!

Sobre a terra, sobre o mar,

As armas! As armas.

Pela Pátria, lutar.

Contra os canhões,

Marchar! Marchar! 
Curiosamente a palavra morte, que aparecia no slogan original da Revolução Francesa de 1789, acabou excluído. Mas no hino da Tunísia permanece. Um de seus versos diz: Nós morreremos em nome de nossa terra. O de Honduras canta: Marcharemos Oh Patria a la muerte! O de Senegal canta Morte, sim! Mas não a desonra. O das ilhas Seychelles inclui Morte em vez de viver na Escravidão! Durante a guerra-fria os americanos costumavam gritar Better dead than Red (Melhor morto que Comunista), expressão provavelmente criado no período da Segunda Guerra Mundial por Joseph Goebbels para estimular as tropas alemãs a lutarem até a morte contra as forças da União Soviética. No Paraguai se canta, República ou Morte!

Mas, em vez de, que relacionam itens contrastantes. É uma coisa ou outra. Noutros casos similares aparece junto ao verbete morte a disjunção ou. Por exemplo, em Cuba, o regime acabou adotando em 1960 o slogan Pátria ou Morte. A bandeira dos 33 Orientales, o movimento encabeçado por Juan Antonio Lavalleja que lutou e separou a Província Cisplatina do Brasil em 1825, afirma a mensagem de Liberdade ou Morte. O Desperte Romeno inclui a expressão "Independência ou Morte!". Cada listra da bandeira grega corresponde a uma sílaba do grito "Liberdade ou morte" proferida na luta contra os otomanos. "Viver Livre ou a Morte" é o slogan do estado americano de New Hampshire. O famoso discurso de Patrick Henry na Convenção do estado americano da Virgínia clamava "Dê-me a liberdade, ou dê-me a morte". $\mathrm{O}$ conhecido grito Independência ou Morte, proferido por Dom Pedro I às margens do Ipiranga, inaugurou a vida brasileira livre do domínio português. Slogan similar, Liberdade ou Morte, pertence aos revolucionários búlgaros de 1876. A mesma expressão foi utilizada numa das bandeiras da luta colonial nos Estados Unidos.

Sob o ponto de vista retórico a disjunção ou é poderosa. Ela revela uma incompatibilidade de alternativas na solução de um dilema. Por isso ela é rotulada como "exclusiva", ou seja, um par de proposições (p, q) deve significar que $p$ é verdadeiro ou que $q$ é verdadeiro, mas não ambos. Este tipo de discurso é radical não autoriza meios-tons. Descrever a utopia política desta forma, como uma jornada que só admite a vitória e nada mais, expressa a vocação de grupos de militantes radicalizados que em todas as épocas dizem ter certezas absolutas.

\section{Considerações finais}

Nem todos militantes de causas radicais foram e são revolucionários no sentido mítico proposto por Marighela em seu Mini manual da guerrilha urbana (pessoas com alta moralidade, pacientes e frias, que atacam e recuam; 
que não se entregam à fadiga, à chuva e ao calor; que não têm medo; pessoas que agem no underground; que são preparadas em táticas, armas, munição e equipamento; móveis; dispostas a atacar as corporações, o governo, os imperialistas e os ricos). Nem todos se martirizam como homens ou mulheres bombas, e nem todos foram e são terroristas, certamente. Mas a combinação destas três figuras -a do revolucionário, a do mártir e a do terrorista- num só personagem revela a face mais dramática e explosiva deste tipo de ator inconformado e mobilizado por uma narrativa de tom redentor. Trata-se de uma minoria hiperativa capaz de marcar uma época e a história com seus atos ao mesmo tempo altruístas e assassinos.

Por isso mesmo, cabe recordar a figura de Edmund Burke, o pensador irlandês que em 1790, ao comparar a revolução francesa com a pacífica e "gloriosa" revolução inglesa antecipou a violência que acabaria imperando na França a partir de 1793. Em decorrência tornou-se pioneiro de uma tradição filosófica de crítica às utopias políticas. O Terceiro Estado seria corrompido pelo poder e pelo interesse econômico, previu ele em Reflexões sobre a Revolução na França. "No horizonte vocês não verão nada além de forcas", disse Burke (2012) ao antecipar o terror jacobino.

No entanto, essa perspectiva de que as revoluções acabam engolindo seus próprios agentes não é partilhada pela tendência oposta, a que preza a "imaginação produtiva" (Ricouer, 2001, p. 30). Nesta visão, a tarefa das narrativas utópicas é explorar o possível. Ocorre que na esfera da idealização não existem limites ao pensamento e a fronteira entre o que se almeja e o que se pode realizar nunca está claramente delineada. O vazio existencial acaba sendo preenchido pela pulsão em tornar real o ideal, às vezes a qualquer custo e a despeito de qualquer obstáculo.

Uma maneira de documentar este apreço do público às narrativas utópicas são as peregrinações políticas e religiosas. É o que se observa, por exemplo, hoje na África do Sul. O culto à Mandiba, o amoroso apelido dado a Nelson Mandela, não se restringe aos nativos. Turistas internacionais são atraídos por sua história de heroica luta contra o apartheid. No passado recente, as figuras de Che Guevara e de Fidel Castro foram capazes igualmente de galvanizar a paixão de uma larga parcela da juventude mundial. Cuba acostumou-se a receber este tipo de turista sedento de revolução. O Chile dirigido por Salvador Allende nos anos 70 serviu também de destino a esse tipo de jornada. Dela participaram em especial jovens ansiosos em testemunhar a criação de uma pátria socialista.

A jornada [em busca] da esperança contém um forte elemento de culto e fé. Tal efeito de encantamento é perceptível também nas jornadas que peregrinos 
fazem a Roma e a Meca, por exemplo. Já se diagnosticou inclusive uma reação obsessiva, a "Síndrome de Jerusalém", o frenesi que afeta anualmente cerca de 50 turistas judeus e cristãos estrangeiros que chegam àquela cidade (de um total aproximado de dois milhões de visitantes em média). Nestes casos em que as pessoas acabam hospitalizadas observa-se um comportamento delirante (a necessidade de se estar limpo, a compulsão por aparar as unhas das mãos e pés, o uso de togas brancas, os gritos de salmos ou versículos da Bíblia, o canto de hinos religiosos e confusos sermões públicos proferidos em lugares considerados sagrados). Tal atitude excêntrica parece ser estimulada pelos elementos místicos existentes no ambiente da cidade (Witztum e Kalian, 1999). No caso da peregrinação à Meca, o número de visitantes cresceu de 90 mil pessoas em 1926 para três milhões em 2010. ${ }^{1}$

Por fim cabe recordar que este tipo de experiência na qual a narrativa utópica é capaz de provocar o êxtase dos ouvintes não é novo. Durante quatro séculos os indígenas Tupi-Guaraní percorreram o continente sul-americano em busca da Terra-Sem-Mal. À frente deles estavam os xamãs. A rota dos peregrinos era sempre definida pelas visões destes homens. Nesta tarefa de animar os espíritos, esses pregadores andavam de tribo em tribo. Evocavam em seus discursos e orações as imagens do paraíso. Diziam que era um lugar de abundância, da perpétua juventude e de felicidade. Em decorrência, as tribos paravam de trabalhar, dançavam dia e noite animadas pelas profecias e aguardavam instruções para chegar àquele destino antes da ocorrência do apocalipse: um dilúvio, segundo os mbüas; a explosão da terra, segundo os nandevas; um ataque de monstros, cavalos voadores e macacos portando flechas chamejantes, conforme os kaiovás (Ochoa Abaurre, 2007; 2002; Eliade, 1982).

\section{Referências}

ACHTERHUIS, Hans. Violent utopias. Peace Review. v. 14, n. 2, p. 157-164, 2002.

BREZNAU, Nate; LYKES, Valeri A.; KELLEY, Jonathan; EVANS, M. D. R. A clash of civilizations? Preferences for religious political leaders in 86 nations. Journal for the Scientific Study of Religion. v. 50, n. 4, p. 671-691, 2011.

BURKE, Edmund. Reflexões sobre a Revolução na França. Rio de Janeiro: Top Books, 2012.

CAMPBELL, Joseph. O herói de mil faces. São Paulo: Cultrix, 2007.

COTTEE, Simon. Mind slaughter: the neutralizations of jihadi salafism. Studies in Conflict and Terrorism, v. 33, n. 4, p. 330-352, 2010.

\footnotetext{
Segundo noticiado pela UPI em 16 nov. 2010.
} 
ELIADE, Mircea. Paraíso y utopia: geografia mítica e escatologia. In: Frank E. Manuel. Utopías y pensamiento utópico. Madrid: Espasa, 1982. p. 312-333.

FANON, Frantz. Black skin, white masks. New York: Grove, 1968.

FANON, Frantz. Os condenados da terra. Rio de Janiero: Civilização Brasileira, 1979.

FELLUGA, Dino. General introduction to narratology. Introduction to narratology. $<$ http://www.cla.purdue.edu/english/theory/narratology> (27 jun. 2014).

GIBSON, Nigel C. Fanonian pratices in South Africa. New York: Palgrave Macmillan, 2011.

HAFEZ, Mohammed M. The alchemy of martyrdom: jihadi salafism and debates over suicide bombings in the Muslim world. Asian Journal of Social Science. n. 38, n. 3, p. 362-376, 2010.

HOLLANDER, Paul. Political pilgrims: Western intelectuals in search of the good society. Piscataway: Transactions Publishers, 1997.

LYOTARD, Jean-François. A condição pós-moderna. Rio de Janeiro: José Olympio, 2008.

OCHOA ABAURRE, Juan Carlosa. Descubrir la ontologia em la mitologia del pueblo tupi-guarani: el reto de una nueva antropología iberoamericana. Thémata: Revista de Filosofia, v. 39, p. 529-537, 2007.

OCHOA ABAURRE, Juan Carlos. Mito y chamanismo: el mito de la Tierra Sin Mal en lós Tupi-Cocomade de la Amazonía peruana. Pamplona: Universidade de Barcelona. Tese de Doutorado, 2002.

RICOUER, Paul. Ideología y utopía. Barcelona: Gedisa Editorial, 2001.

RICOUER, Paul. Tempo e narrativa. Campinas: Papirus, 1995.

TROTSKY, Leon. Terrorismo e comunismo: o anti-Kaustky, Rio de Janeiro: Editora Saga, 1979.

WITZTUM, Eliezer; KALIAN, Moshe. The “Jerusalem syndrome”. Israel Journal of Psychiatry and Related Sciences, v. 36, n. 4, p. 260-271. 1999.

Autor correspondente:

Jacques A. Wainberg

Av. Ipiranga, 6681, Prédio 7, sala 319

90619-900 Porto Alegre, RS, Brasil

Recebido em: 29 ago. 2013

Aprovado em: 26 jun. 2014 